\title{
FORMALIDADES DEL MATRIMONIO EN EL CÓDIGO GENERAL DEL PROCESO*
}

Formalities of Marriage in the General Code of Procedure*

\section{Alcides Morales Acacio**}

Fecha de Recepción: Mayo 6 de 2013

Fecha de Aceptación: Mayo 13 de 2013

SUMARIO: 1. Introducción; 2. Nociones previas; 2.1. El concepto de matrimonio y su análisis; 2.2. Naturaleza jurídica del matrimonio en Colombia: teoría contractualista; 2.3 Lo que formalmente rige en vigencia del Código General del Proceso; 3. Conclusiones; 4. Referencias bibliográficas.

"Artículo de investigación producto de los estudios realizados en medio de la Cátedra de Derecho de Familia impartida en la Universidad de Cartagena. Realizados con recursos propios.

"Abogado Universidad Nacional de Colombia, Especialización en Derecho de Familia UNAB. Exmagistrado, Sala Civil - Familia, Tribunal Superior. Profesor Titular Dpto. de Derecho Privado - Facultad de Derecho, Universidad de Cartagena. Miembro de la Academia Colombiana de Jurisprudencia. Autor de cinco libros de Derecho de Familia, con Editorial Leyer y con Editorial Doctrina y Ley. 


\section{COMO CITAR ESTE ARTÍCULO (APA 6th)}

Morales Acacio, A. (2013) Formalidades del matrimonio en el código general del Proceso. (Y. Carrillo De la rosa, Ed.) Revista Mario Alario D'filippo V(10), págs. 10-23

\section{RESUMEN}

En esta investigación se apreciarán las distintas normativas existentes para la celebración del matrimonio, a partir de la entrada en vigencia del Código General del Proceso, en las cuales quedaron derogados algunos artículos del Código de Procedimiento Civil. Por ello, es perentorio realizar un análisis holístico y jurídico del contrato sinalagmático del matrimonio en el nuevo Código General del Proceso para verificar su validez jurídica, con el propósito de identificar las nuevas formalidades existentes y su apoyo legal. Se encontrarán en la investigación todos los cambios introducidos por el legislador, encaminados a brindar eficacia procesal a este contrato.

\section{PALABRAS CLAVE}

Matrimonio, celebración, judicial, notarial, testigos, juez, notario, oposición, acta, derogación, vigencia.

\section{ABSTRACT}

In this research we find the different existing regulations for marriage, from the entry into force of the General Code of Procedure, which were repealed in some articles of the Code of Civil Procedure are appreciated. Therefore, it is imperative to conduct a legal analysis of holistic and mutually binding contract of marriage in the new General Code of Procedure to verify their legal status, with the purpose of identifying existing and new formalities and legal support. All changes made by the legislature, aimed at providing procedural efficiency to this contract will be in research.

\section{KEYWORDS}

Marriage, celebration, legal, attorney, witnesses, judge, notary, opposition, act, repeal, effective. 


\section{INTRODUCCIÓN}

Es tan importante el matrimonio, que del derecho comparado se rescata como característica que la mejor manera de organización familiar es la monogámica y la matrimonial. Ahora bien, el origen de la familia es la voluntariedad de los seres humanos, de vivir juntos de forma permanente y singular; pero si se ratifica con el matrimonio, se llega al sistema ideal, en todos los países desarrollados del mundo. $Y$ ese matrimonio civil que regula la ley del Estado que para nosotros es un contrato, naturaleza jurídica heredada de la revolución francesa; es además solemne, Artículo 113 y 115 C.C.; que para que tenga connotación jurídica debe cumplir requisitos para su validez, referidos a las cualidades personales de los contrayentes, o considerados en sí mismo como personas, que son los de fondos: positivos, que deben darse, como la diferencia de sexo y la capacidad sexual; capacidad mental o capacidad por la edad, plena o relativa; y, la manifestación de la voluntad, sustancial o formal. Los negativos de fondos, que deben inexistir, tales como, la inexistencia de un vínculo matrimonial anterior, la inexistencia de un vínculo de parentesco; y, la no complicidad en el conyugicidio. Los de formas, anteriores al matrimonio, coetáneos y posteriores a la celebración. Es en estos últimos requisitos, referidos a la manera como se celebra el matrimonio, que el Código deroga totalmente los artículos 126, 128, 130 y 133, y parcialmente el 129, disposiciones que se estudian y analizan en el texto de este artículo.

\section{NOCIONES PREVIAS}

\subsection{EL CONCEPTO DE MATRIMONIO Y SU ANÁLISIS}

Para el Código Civil nuestro en su artículo 113: "El matrimonio es un contrato solemne por el cual un hombre y una mujer se unen con el fin de vivir juntos, de procreary de auxiliarse mutuamente".

De esa definición contenida en la norma del artículo señalado se deduce para su análisis:

a. Que el matrimonio requiere un acuerdo de voluntades, es natural, porque el término contrato que utiliza el texto del artículo supone obviamente el concurso de voluntades libres entre quienes lo celebran, expresado con el cumplimiento de las formalidades y requisitos establecidos en el Código Civil, ante el juez civil o promiscuo municipal del domicilio de cualquiera de los contrayentes a prevención ${ }^{1}$, o jueces municipales de pequeñas causas y competencias múltiples. Y esos requisitos se refieren a que se den las cualidades que deben reunir los contrayentes en sí mismos considerados, esto es, los requisitos positivos de fondo y que no existan entre ellos los requisitos negativos de fondo, que de darse impiden en forma dirimente la celebración; las formalidades las determina el, entonces vigente, Código Civil a partir del Artículo 126 y constituyen, en general, los requisitos de forma. (Esos requisitos positivos de fondo, que deben darse

\footnotetext{
${ }^{1}$ La Corte Constitucional, mediante fallo integrador C-112 de 9 de febrero de 2000. M.P Alejandro Martínez Caballero, declaró exequible el Artículo 126 del Código Civil (Art. 126)- El matrimonio se celebrará ante el juez del distrito de la vecindad (de la mujer), con la presencia y autorización de dos testigos hábiles, previamente juramentados), tal y como fue modificado por el Artículo $7^{\circ}$ del Decreto 2272 de 1989, con excepción de la expresión entre paréntesis (de la mujer) que fue declarada inexequible, "en el entendido de que, en virtud del principio de la igualdad de los sexos (C.P Arts. 13 y 43, Decreto 2820 de 1974), el juez competente para celebrar el matrimonio es el juez civil municipal o promiscuo municipal de la vecindad de cualquiera de los contrayentes.
} 
para que el matrimonio valga, son: primero, la diferencia de sexo y la capacidad sexual; pues, el matrimonio se celebra entre un hombre y una mujer, que además de sexos diferentes, puedan hacer las relaciones sexuales, y engendrar y concebir; para que el matrimonio valga, así no se tengan hijos. El Artículo 42 de la Constitución ratifica lo dicho. Segundo, la capacidad mental o capacidad por la edad; se refiere a la capacidad reflexiva para entender que se va hacer en el matrimonio, que la ley considera la tienen los mayores de dieciocho años de maneara plena; y relativa, los mayores de catorce hombre y mujer, menores de dieciocho años. Relatividad que se complementa (para que llegue a plena) con la autorización o permiso de los padres, ascendientes ordenadamente, curador o guardador, según el caso; en tercer lugar, la manifestación de la voluntad libre de los vicios que en materia de matrimonio invalidan el consentimiento (error, fuerza o violencia). Esa voluntad se manifiesta ante el juez competente de manera directa o por apoderamiento. (Mazeaud, 1959)

Los requisitos negativos de fondo, los que no deben darse para que el matrimonio valga, los enunciamos así: Inexistencia de vínculo matrimonial anterior, inexistencia de vínculo de parentesco, en cierto grado, y la no complicidad en el conyugicidio.

Los requisitos de formas: se refieren a la manera como se celebra la diligencia de matrimonio, son anteriores a la celebración: aviso al juez y publicación; coetáneos: lugar, juez, testigos presenciales, presencia de los contrayentes directamente o por apoderado, declaración de voluntad, acta de matrimonio. (Requisitos posteriores, el registro del acta, una vez protocolizada la diligencia).

En igual sentido, la sentencia de la Corte declaró inexequibles las expresiones "de la mujer" y "del varón" del Artículo 131 del Código Civil y "de la mujer" contenida en la frase "el matrimonio se celebrará ante notario del círculo del domicilio de la mujer" del inciso primero, del artículo primero del Decreto 2668 de 1988, en el entendido que son competentes para la celebración del matrimonio el juez o notario del domicilio de cualquiera de los dos contrayentes.

b- La necesidad de guardarse fidelidad, pues la norma también singulariza cuando prescribe que el matrimonio debe ser entre un hombre y una mujer; pues, en virtud de la monogamia, cada uno de los cónyuges debe guardarse fe, esto es reservarse sus cuerpos para la satisfacción ordenada de los apetitos sexuales, dentro de un ambiente de ética y de respetabilidad y para las caricias y contemplación. Esa fidelidad que impide la realización de las relaciones sexuales con personas diferentes a su cónyuge, es lo que la doctrinaria y jurisprudencialmente se conoce como fidelidad material y contempla además la infidelidad ética o moral que obliga al marido o a la mujer a inhibirse de relaciones platónicas con extraños, posar desnudos sin autorización del otro, los actos de tipo sexual que no implican la cópula fornicaria, los actos de lascivia o impúdicos, los comportamientos contrarios al decoro, respeto mutuo, recato, y en fin a la consideración que se deben los cónyuges, ocasionados con palabras, con escritos, hechos, actitudes, cuando reviste el calificativo de grave según las circunstancias particulares, es decir, de acuerdo con la educación y estado social de los casados, con costumbres y tradiciones, con el entorno o ambiente, etc., los cuales aunque no alcanzan a configurar trato sexual alguno, por lo menos, constituyen violaciones al deber de fidelidad moral, como quiera que por ejemplo, cualquier relación aun 
simplemente sentimental con persona diferente al cónyuge bien puede crear la apariencia o el aspecto exterior de una relación amorosa y, por ende, herir la susceptibilidad del cónyuge inocente, sentencia del 19 de julio de 1989, de la Honorable Corte Suprema de Justicia. (Corte Suprema de Justicia-Sala de Casación Civil, 1989)

c- La necesidad de integrar una comunidad doméstica, es decir, que el hombre y la mujer que por el matrimonio van a vivir juntos con sus hijos lo hagan bajo un mismo techo, que es lo que se llama familia en sentido restringido, caracterizada esencialmente por el parentesco y la comunidad doméstica.

d- La satisfacción ordenada de las relaciones sexuales, pues el fin principal del matrimonio es la cohabitación, el que los casados puedan satisfacerse sexualmente, que es lo que consuma el matrimonio, haciéndolo válido siempre y cuando haya en cada uno de los casados la capacidad de procrear, así ellos acuerden no tener hijos, pues la procreación es en el matrimonio civil una consecuencia, aunque se repite es esencial que los cónyuges tengan la capacidad de tenerlos.

e- El deber que tienen los cónyuges de auxiliarse mutuamente, es decir el de socorrerse y ayudarse mutuamente; o la obligación de que se asistan recíprocamente, que tiene que ver con la ayuda material o económica y la moral o intelectual: la primera se traduce en que se den los alimentos, entendiéndolos en sentido amplio a que se refiere el Artículo 133 del Código del Menor: comida, alojamiento, vestido, asistencia médica, formación integral e instrucción; la segunda, comprende lo que cada uno de los cónyuges pueda necesitar del otro frente a las dificultades de la vida: asistencia en la vejez y en las dolencias, que se acepten las situaciones de pobreza o enfermedad de alguno de los esposos compartiendo las alegrías y las penalidades, el trato considerado, digno y decoroso la prestación de estímulos necesarios para el logro de las empresas en las que cada uno esté interesado.

El Artículo 176 C.C. ratifica esta obligación cuando dice, a más de guardarse fe, que los cónyuges deben ayudarse y socorrerse en todas las circunstancias de la vida y el art. 179 ibídem que en su inciso segundo prescribe que: "los cónyuges deben subvenir a las ordinarias necesidades domésticas en proporción a sus facultades".

f- El respeto mutuo que se deduce de la convivencia pacífica en que deben transcurrir las relaciones familiares resultando como el entorno adecuado y preciso para que se cumplan las obligaciones que se originan en el matrimonio, el que los cónyuges se respeten o se permitan el desarrollo de su personalidad, la tolerancia recíproca en la vida familiar, sin que se ultrajen, se traten de manera cruel o se maltraten de obra, que no se causen vejámenes, que no se hieran en su honor ni en su justa sensibilidad

\subsection{NATURALEZA JURÍdiCA DEL MATRIMONIO EN COLOMBIA: TEORÍA CONTRACTUALISTA}

En nuestra legislación, nosotros sabemos, sin que este conocimiento tenga el menor asomo de duda, por lo que la máxima compilación sustantiva predica, cuando define lo que es el matrimonio 
en el Artículo 113, que este es un contrato. Entonces, para nosotros la controversia que opera en el derecho comparado, no tiene cabida porque la exégesis de la norma contenida en el artículo sobredicho nos salva de aquella discusión cuando de manera más que expresa es inequívoca en la prescripción de hacer y definir, que el matrimonio sea un contrato, al que califica de solemne y entendida así la disposición hay que suponer que la fuente de su nacimiento sea un acuerdo de voluntades y siempre que el derecho se sirve del término contrato es obvio que hay que entender un acuerdo de voluntades que aquí es entre los esposos. El cual comprende una declaración de voluntad formal y una de fondo. La primera alude a que los contrayentes digan ante funcionario competente de manera perceptible, sin fórmulas especiales, que se casan, o que se aceptan como marido y como mujer; y la de fondo o material significa que esos esposos sepan que deben cumplir unas obligaciones inherentes al matrimonio como la de cohabitar, la de guardarse fe o fidelidad, integrar una comunidad doméstica, ayudarse y socorrerse mutuamente en todas las circunstancias de la vida. Por eso el matrimonio para el derecho civil, o más bien para el derecho de familia, es contrato gústenos o no. Y su solemnidad la define además el Artículo 115 del mismo código. Esas dos normatividades dejan aclarado cualquier planteamiento, que se pretenda hacer al respecto a la naturaleza jurídica del matrimonio, si se obedece a la literalidad de la norma, pues, el legislador es demasiado claro en lo pertinente, por lo menos es esa forma de interpretación de la norma, que es la de mayor elementalidad porque resulta a simple vista.

Miremos lo que reza la disposición:

"El matrimonio es un contrato solemne por el cual un hombre y una mujer se unen con el fin de vivir juntos, de procrear y de auxiliarse mutuamente".

Lo que prevé la transcripción, en su contexto, es un concurso de voluntades que se realiza con la finalidad de producir un fin jurídico; lo que sucede es que esa modalidad de contrato no es igual a los acuerdos de voluntades comunes y corrientes, como las del Art. 1495 C.C., donde se pactan obligaciones patrimoniales entre los contratantes, imponiéndoles términos o condiciones y resolver lo pactado por mutuo disenso, Art. 1602 C.C.; en efecto, el matrimonio en cuanto a su voluntad formal concede plena y absoluta libertad a quienes se casan de decidir si contraen el matrimonio; pero en cuanto a las obligaciones que de ese acto se derivan como no dependen de la voluntad de las partes sino de la ley, en donde el mutuo consenso no juega ningún papel, a más de que tampoco existe libertad para ponerle términos o condiciones a las obligaciones que los cónyuges adquieren con el matrimonio (es el derecho de familia personal, o en sentido estricto); ahora la razón para que no haya libertad en definir las obligaciones que surgen una vez realizado el matrimonio es que ellas sean de orden público, impuestas por la ley, que las hace inmodificables, porque pertenecen al derecho de familia personal. (Morales, 2006)

Pero el matrimonio es un contrato solemne, ratifica el Artículo 113.

Quiere ello decir que para que valga, en su celebración se exigen ciertas formalidades indispensables y determinadas por la ley, sin cuya observancia no tendrá valor ni efecto legal alguno, todas se deben cumplir ante el funcionario competente, que es el juez civil municipal o promiscuo municipal de la vecindad de cualquiera de los contrayentes, a prevención (sentencia C- 
112 de febrero 9 de 2000 de la Corte Constitucional), como lo señalan otras normas como los Artículos 115 y 126 del C.C; y, el Juez Municipal de Pequeñas Causas y Competencias Múltiples, según el Artículo 14 de la Ley 1395 de 2010:

"Art. 115.- El contrato de matrimonio se constituye y perfecciona por el libre y mutuo consentimiento de los contrayentes, expresado ante el funcionario competente, en la forma y con las solemnidades y requisitos establecidos en este código, y no producirá efectos civiles y políticos, si en su celebración se contraviniere a tales formas, solemnidades y requisitos".

Nótese como el legislador es reiterativo en su concepción contractualista de la institución matrimonial y de su solemnidad, no dejándole al intérprete alternativa, se repite, en cuanto al sentido claro de la ley, lo que inhibe desatender su tenor literal a pretexto de consultar su espíritu. (Art. 27 C.C.)

El matrimonio es entonces para la ley colombiana, un contrato. Esta afirmación es innegable a la luz de los artículos citados.

Claro que, si se tiene en cuenta que la declaración de voluntad, o el mutuo consentimiento de los esposos, ante el funcionario competente comprende una declaración formal y otra de fondo o material, podemos distinguir allí la existencia de dos situaciones que también podrían definir la naturaleza jurídica del matrimonio, sin demeritar la ya expuesta conforme a los dictados del Artículo 113. Ellas son primeramente, que el consentimiento prestado para contraer matrimonio genera un acto constitutivo del matrimonio, que sería el matrimonio-acto, un acto jurídico familiar, en evidencia, dado que para que se perfeccione se necesita ese acuerdo de voluntades encaminadas a producir efectos jurídicos, particularmente un estado conyugal o estado familiar. (Morales, 2007)

En segundo lugar el acuerdo expreso de voluntades se refiere a que quienes se casan conozcan para qué lo hacen, esto es, que sepan que van a cohabitar, a integrar una comunidad doméstica, guardarse fidelidad, ayudarse y socorrerse mutuamente para toda la vida; y como estas obligaciones las define la ley sin que para nada intervenga la voluntad de los contrayentes y van específicamente a regular la vida de los cónyuges, se da también lo que se ha denominado el matrimonio-estado, un conjunto de deberes que no provienen de las partes y que ellas tampoco pueden modificar y a los cuales quedan sometidos a consecuencia del acto constitutivo del matrimonio que es lo que se llama matrimonio-acto.

\subsection{LO QUE FORMALMENTE RIGE EN VIGENCIA DEL CÓDIGO GENERAL DEL PROCESO}

En cuanto a este aspecto formal del matrimonio, exigido para su validez, hay nuevas orientaciones jurídicas, por cuanto el Código General del Proceso ha hecho las siguientes derogaciones en el literal a del Artículo 626, que sigue a continuación:

a) A partir de la promulgación de esta ley quedan derogados: Artículos 126,128, la expresión "y a recibir declaración a los testigos indicados por los solicitantes" del Artículo 129. 
Los artículos 130 y 133, quedan derogados.

La expresión "practicadas las diligencias indicadas en el Artículo 130" del Artículo 134; del Artículo 136 se derogan las expresiones " $y$ no hubiere por este tiempo de practicar las diligencias de que habla el Artículo 130". Y "sin tales formalidades".

Artículo 126

Es inequívoca su derogatoria porque el literal a del Artículo 626 del C.G.P, así lo afirma, a partir de su vigencia; es decir, desde la Ley 1564 de 2012.

Pero como existe la regulación del matrimonio civil en vigencia, también, inobjetable, hasta hoy, en el Artículo 113 del CC., como la forma deseada y mayoritaria en la organización de la familia en Colombia. Debe haber un funcionario competente con potestad jurisdiccional, capaz funcionalmente de realizar esa celebración; operador judicial al que, quienes acuerden casarse civilmente asisten para lograrlo. Y es este mismo C.G. del P. el que al definirle la competencia al Juez Civil Municipal en única instancia, le señaló para ello, en su Artículo 17, numeral 3. Así lo refiere esta normativa específicamente:

"Los Jueces Civiles Municipales conocen en única instancia:...3‥ De la celebración del matrimonio civil, sin perjuicio de la competencia atribuida a los notarios".

Es indudable este señalamiento, que habrá de entenderse obvio por cuanto siempre habrá un Juez para contraer matrimonio, cerca; pues siempre los contrayentes residirán en un lugar, que aunque muy remoto, integre esa comprensión territorial, en nuestra división política y administrativa del país.

Desde luego que la misma competencia la tienen los Jueces Promiscuos Municipales del domicilio o residencia de uno de los contrayentes, a su elección, según igualdad para hombre y mujer que el derecho positivo, define por la sentencia C-112 de 9 de febrero de 2000 que adicionó lo que ya había predicho el Decreto 2820 de 1974, el de la igualdad de los sexos. Por suerte que uno de esos Jueces Civiles Municipales, Promiscuos Municipales del sitio de residencia de cualquiera de los contrayentes, tiene competencia; quedando así garantizado en este sentido, el acceso a la justicia de los que deseen casarse por lo civil; sin perjuicio de optar por hacerlo ante un notario. Pues, en Colombia existe un matrimonio civil de regulación legal: el judicial ante el Juez, y el notarial ante este funcionario.

Y como el C. G. P. no hace derogatoria al Artículo 14 de la Ley 1395 de 2010, en su numeral 3 parágrafos 1,2 y 3 esta misma competencia la mantienen los señores Jueces Municipales de Pequeñas Causas y Competencias Múltiples.

En síntesis, son jueces competentes para celebrar el matrimonio civil, los Civiles Municipales, Promiscuos Municipales; y, los Jueces Municipales de Pequeñas Causas y Competencias Múltiples, del lugar de residencia de uno de los contrayentes a su elección. Queda así determinado ante quien 
se cumple este requisito de forma coetáneo o concomitante a la celebración del matrimonio para que tenga completa validez; solemnidad exigida, también, por lo que predica el Artículo 115 del C.C.

El Artículo 128, prescribía que los que querían contraer matrimonio civil concurrían verbalmente o por escrito ante el Juez competente a manifestarle este propósito para que iniciara el trámite de la diligencia y los casara; pero esa norma que también preveía lo que debía contener la solicitud o aviso al Juez, la derogó el mismo literal a del Artículo 626 del C. G. P.

Pues bien, si los seres humanos, hoy hombre y mujer, (Artículos 113 del C.C.; 42 inc. 1ㅇ de la Constitución) desean vivir juntos de manera permanente, y singular; y además quieren ratificarlo con el matrimonio civil judicial para el que ya sabemos que son competentes los Jueces Civiles Municipales, Promiscuos Municipales y los Municipales de Pequeñas Causas y Competencias Múltiples, tendrán que decírselo; sin darle ese aviso o solicitud, no podrán casarse nunca ante uno de ellos, según el caso. Pues, no habría forma, por cuanto sin ese conocimiento no tendría lugar el acto de celebración de esas nupcias por lo civil, ante uno de los jueces de competencia.

Ahora bien, el artículo que contenía esa disposición, no rige. Entonces, ¿cómo se hace para hacer la solicitud de este matrimonio? o ¿cómo se le pide al Juez del conocimiento que lo celebre? Como también se sabe que debe haber solicitud por el contenido del Artículo 129 del C.C. que dice que el juez procederá inmediatamente a practicar las diligencias que conciernen a su celebración, (como la obtención de permiso, cuando fuere el caso; el requerimiento que hará el juez de la vecindad del domicilio escogido para casarse al del otro, para que haga la publicación por edicto durante quince días, cuando este otro contrayente no tenga seis meses de residencia en él para la fijación del edicto. Y dar a conocimiento o a publicidad el mentado matrimonio). Habrá que acudir, por el método de la interpretación sistemática de la ley, a lo que para el notario se da según los Artículos 1 y 2 del Decreto 2668 de 1988, que es lo que legalmente existe, en cuanto a la solicitud o aviso para la celebración. Para que lo que se tiene para el notario, sea lo mismo que se da para el juez. Competente para celebrar el matrimonio. $Y$ en ese mismo sentido se tiene para el notario, que como se dijo, también es para el juez, lo siguiente:

El Decreto 2668 de 1988 en su Artículo 1ํindica que podrá celebrarse el matrimonio civil; y en cuanto a los menores adultos requieren permiso de sus representantes legales. En el Artículo 20:

"En la solicitud que deberá formularse por escrito y presentarse personalmente ante el notario por ambos interesados o sus apoderados, se indicará:

a) Nombre, apellidos, documento de identidad, lugar de nacimiento, edad, ocupación y domicilio de los contrayentes y nombre de sus padres.

b) Que no tienen impedimento legal para celebrar matrimonioy

c) Que es de libre y espontánea voluntad unirse en matrimonio. 
Cuando los interesados pretendan legitimar a sus hijos extramatrimoniales comunes no reconocidos, deberán designarlos en la solicitud".

En el artículo 3ㅇ:

"Al escrito al que se refiere el artículo anterior, los pretendientes acompañarán copias de los registros civiles de nacimiento, válidos para acreditar parentesco, expedidas con antelación no mayor de un (1) mes a la solicitud del matrimonio".

Queda, en cuanto a la solicitud o aviso y a su contenido muy definido, como hay que hacerlo. Sin que haya dudas de cómo deben actuar los contrayentes del matrimonio civil para casarse ante un juez.

El artículo 12 C.G.P. en relación con los vacíos y deficiencias salva cualquier clase de dudas al respecto cuando prescribe:

"Art. 12 cualquier vacío en las disposiciones en el presente código se llenará con las normas que regulen casos análogos. A falta de estas, el juez determinará la forma de realizar los actos procesales, con observancia de los principios constitucionales y los generales del derecho procesal procurando hacer efectivo el derecho sustancial".

En lo que concierne al Artículo 130, en cuanto a la declaración de testigos y fijación por edicto, también derogado todo queda infinitivamente claro, contenía la norma que el juez competente frente a la solicitud de matrimonio, procedía inmediatamente a recibir las declaraciones de los dos (2) testigos hábiles indicados por los solicitantes (parte derogada igualmente del Artículo 129). Evidentemente claro por cuanto ya no hay que presentar testigos, si no los exigen la norma, para que declaren sobre si en los contrayentes se dan o no los requisitos de validez exigidos para el matrimonio, (de acuerdo con los preceptos de los Artículos 113 y 115 del C.C.), o si existen o no impedimentos para casarse. Igual al matrimonio civil notarial que no requiere de esa formalidad, quizás porque en ese matrimonio la solicitud debe decirlo, por la derogatoria a los Artículos 129 en lo que concierne "a recibir declaración a los testigos indicados por los solicitantes", y 130 que hace el C.G.P., en su Artículo 626, literal a.

Sin embargo, se tiene que el Artículo 135 del C.C., aún vigente, cuando regula la celebración del matrimonio civil, señala:

"El matrimonio se celebra presentándose los contrayentes en el despacho del juez, ante este, su secretario y dos testigos. El juez... Enseguida se extenderá un acta de todo lo ocurrido que firmarán los contrayentes, los testigos, el juez y su secretaria; con lo cual se declara perfeccionado el matrimonio".

Ello indica que si hay testigos, no para declarar sobre si en los contrayentes se dan las cualidades personales o requisitos de validez del matrimonio. Sino para presenciar el matrimonio simplemente. Es por eso, también, que el Artículo 127, que, hoy quedó aplicable, en relación a los testigos dice en su encabezamiento: 
"Art 127. No podrán ser testigo para presenciar y autorizar un matrimonio:(...)".

Hay, entonces, testigos en el matrimonio, pero para presenciarlo y firmar el acta, más no, para declarar, sobre las cualidades de los contrayentes, como lo exigía el Artículo 130, que esta derogado. Y eso permite decir que en la solicitud de matrimonio se debe consignar los nombres de dos testigos hábiles pero para que presencien su celebración y firmen el acta del mismo, Artículo 135 C.C.

El Artículo 131, sobre domicilios diferentes de los contrayentes dice que:

"Si los contrayentes son vecinos de distintos distritos parroquiales, o si algunos de ellos no tiene seis meses de residencia en el distrito en que se halla, el juez de la vecindad (de la mujer) requerirá al juez de la vecindad (del varón) para que fije el edicto de que habla el artículo anterior, y, concluido el término se lo envíe con nota de haber permanecido fijado quince días seguidos. Hasta que esto no se haya verificado, no se procederá a practicar ninguna de las diligencias anteriores".

La Corte Constitucional mediante la sentencia C-112 de 9 de febrero de 2000 (Corte Constitucional, 2000) declaró inexequible la expresión "de la mujer, en el entendido de que en virtud del principio de igualdad entre los sexos (D. 2820 de 1974), se trata del juez de la vecindad de aquel contrayente, cuyo domicilio fue escogido por los futuros cónyuges como lugar para celebrar el matrimonio. En la misma sentencia declaró inexequible la expresión "del varón" en el entendido de que se trata del juez de la vecindad del otro.

\section{El Artículo 132, respecto a la oposición señala:}

"Si hubiere oposición y, la causa de esta fuere capaz de impedir la celebración del matrimonio, el juez dispondrá que en el término de ocho días, los interesados presenten las pruebas de la oposición, concluidos los cuales señalará día para la celebración del juicio y citadas las partes, se resolverá la oposición dentro de los tres días después de haberse practicado esta diligencia".

En cuanto al Artículo 131, muy a pesar de que el Artículo 130 es derogado en su integridad, lo que imperativamente hace concluir que no es necesario presentar testigos, ni hay declaraciones de ellos, obviamente; ni publicación por edicto por el término de quince días para enterar a la comunidad del matrimonio a celebrarse. El Artículo 131 actual mantiene vigente en su contenido que cuando los contrayentes son vecinos de distintos distrito parroquiales o si alguno de ello no tiene seis meses de residencia en el distrito en que se halla, el juez de la vecindad de aquel contrayente cuyo domicilio fue inicialmente escogido de consuno por los futuros cónyuges como lugar para celebrar el matrimonio, requerirá al de la vecindad del otro para que fije el edicto de que habla el artículo anterior, (el 130 derogado totalmente), y concluido el término se le envíe con nota de haber permanecido fijado quince días seguidos; es decir, una vez hecha la publicación del matrimonio pretendido; es cumplido esto que el juez requirente o comitente, procederá con las diligencias que sobrevienen, o sea que hasta que no se haya verificado esa publicación, no se procederá a practicar ninguna de las diligencias ulteriores. 
Vistas así las cosas, en definitiva, lo que no se permite hoy, según derogatoria sabida es que los que van a contraer matrimonio hagan solicitud al juez, presenten los dos testigos hábiles para que declaren sobre cualidades de los contrayentes, ni que el juez que se escoja inicialmente para celebrar el matrimonio lo publique mediante la fijación por quince días en la secretaria de su despacho, ese juez de competencia para celebración del matrimonio ya no tiene que hacer eso. Se repite esa norma fue derogada, el Artículo 130.

Pero si los que se van a casar son vecinos de municipios o distritos parroquiales diferentes, o si alguno de ellos no tiene seis meses de residencia en el distrito o municipio que se encuentra. Entonces, sí, el juez de esa vecindad, si debe requerir al de la otra vecindad para que haga la publicación por los quince días y cumplida devuelva lo hecho según requerimiento para continuar con la celebración.

A menos que ese juez del conocimiento escogido inicialmente, también por la vía de la interpretación sistemática de la ley, de acuerdo con el Artículo 4 del Decreto 2668 de 1988, haga la publicación por el término de cinco días como el notario debe hacerlo en su trámite que le impone este decreto para celebrar el mismo matrimonio civil notarial. Sigue siendo esta una alternativa jurídica, la aconsejable si, se hace la publicación, atendiendo que el propósito de quien legisla con CGP es agilizar el trámite.

O porque como el Artículo 131 actual deja con vigencia la fijación por edicto en su caso específico: cuando los que se van a casar son vecinos de distintos distritos parroquiales o municipios, o si alguno de ellos no tiene seis meses de residencia en el distrito en que se halla, el juez de esta vecindad requerirá al de la vecindad de aquel otro para que se haga la publicación por edicto durante quince días seguidos y vencido este término se lo regrese con nota de haberlo publicado, fijándolo por este tiempo seguido; se aplique por analogía especifica esa publicación, que también pudiera ser.

Lo que conllevaría a concluir que la derogatoria del 130 solo eliminó el requisito de la solicitud y los testigos y suprimió la publicación que su norma prescribía. Por cuanto al disponerla el Artículo 131 para ese caso específico, se aplique de todas formas en el primer evento; cuando se trata del juez de la vecindad de aquel contrayente cuyo domicilio fue escogido por los futuros cónyuges como lugar para celebrar el matrimonio. Debiéndose hacer la fijación en edicto como lo dispone la norma contenida en el Artículo 131 del Código Civil.

Quedarían estas alternativas: a. que el Juez Municipal o Promiscuo Municipal o Municipal de Pequeñas Causas y Competencia Múltiples, acordado primeramente para el matrimonio haga la publicación, fijando el edicto por cinco días seguidos como en el caso del matrimonio ante notario, b. O la fijación por edicto por el término de quince días seguidos en la secretaría que es la que ordena el Artículo 131; pues, esta norma quedó aplicable en la publicación fijando el edicto por quince días cuando el juez escogido inicialmente conoce que uno de los que van a casarse no tiene seis meses de residencia en el lugar del municipio donde se halla o porque los contrayentes sean de municipio o distritos parroquiales distintos; c. que como el artículo 130 quedó derogado, no haya ninguna publicación, ni declaraciones de testigos. 
Acogemos la fijación mediante edicto durante el término seguido de cinco días que es lo que impone la norma del Artículo 4 del Decreto 2668 de 1988, por cuanto se abrevia la diferencia del acto de la celebración. Primero, porque según el Artículo 132 del C.C. el juez, si la hay, debe tramitar y resolver la oposición y segundo porque al eliminarse los testigos para declarar, se persigue con ello agilizar el trámite; tercero porque los quince días de fijación del edicto por el juez de la otra vecindad, sería no respetar la derogación del Art. 130.

En cuanto al Artículo 132 del Código Civil, la oposición para el matrimonio subsiste, tanto que el juez del conocimiento, cuando advierta que la causa que presente el oponente fuere capaz de impedir la celebración del matrimonio dispondrá, su trámite, de la manera prevista en la norma, debiendo decidirla, pero esa resolución, hoy no tiene recursos dado que el Artículo 133 que consagra la apelación y la queja como medio de impugnación fue derogado por el CGP en su literal a del Artículo 626.

Si se da la oposición y la causa de esta fuere capaz de impedir la celebración del matrimonio, el juez dispondrá que en el término siguiente de ocho días, los interesados presenten las pruebas, prelucido ese tiempo "señalará día para la celebración del juicio", y citada las partes, se resolverá la oposición dentro de los tres días después de haberse prelucido esta diligencia.

Y si no se hiciere oposición, o si haciéndose se declara infundada, se procederá a señalar día y hora para la celebración del matrimonio, que será dentro de los ocho días siguientes; esta resolución se hará saber inmediatamente a los interesados. (Artículo 134 C.C.)

\section{CONCLUSIONES}

El Artículo 136 del C.C., que regula el matrimonio en estado de necesidad, in extremis, in artículo mortis, solo le fue derogado estas partes: " $y$ no hubiere por este tiempo de practicar las diligencias de que habla el Artículo 130", y, la expresión "sin tales formalidades".

Por tanto su vigencia comprende, "cuando alguno de los contrayentes o ambos estuvieren en inminente peligro de muerte, podrá procederse a la celebración del matrimonio, siempre que los contrayentes justifiquen que no se hallan en ninguno de los casos del Artículo 140. Pero si pasados cuarenta días, no hubiere acontecido la muerte, que se temía, el matrimonio no surtirá efectos, sino se revalida observándose las formalidades legales". 


\section{REFERENCIAS BIBLIOGRÁFICAS}

CORTE CONSTITUCIONAL. (9 de febrero de 2000) Sentencia C-112. Colombia: Corte Constitucional.

CORTE SUPREMA DE JUSTICIA-SALA DE CASACIÓN CIVIL. (19 de julio de 1989) Sentencia. Colombia: Corte Suprema de Justicia.

MAZEAUD, J. (1959) “Lecciones de Derecho Civil”. Buenos Aires: Ediciones Jurídica.

MORALES, A. (2006) "Lecciones de Derecho de Familia”. Bogotá DC: Leyer.

MORALES, A. (2007) "El divorcio en la legislación colombiana, jurisprudencia y doctrina”. Bogotá DC: Doctrina y Ley. 